President, I. Fankuchen, Polytechnic Institute of Brooklyn; Vice-president, R. W. G. Wyckoff, National Institute of Health; Secretary, H. T. Evans, jun., Philips Laboratories, Inc., Irvington-on-Hudson, N.Y.; and Treasurer, J. Karle, Naval Research Laboratories. Thus at the beginning of this year the American Crystallographic Association was firmly established. The charter membership now stands at 495, and plans have been made for the first meeting to be held this month at Pennsylvania State College. Two meetings will be held yearly, and the publications and activities of the two former Societies will be continued and expanded.

\section{MECHANISM OF COMBUSTION IN GASES}

A $\mathrm{N}$ international conference on the kinetics and A mechanism of burning and combustion reactions in the gaseous phase was held in Paris during April 26-May 1, 1948, in the Reunion Hall at the French Institute of Petroleum. The conference was organised by the National Centre of Scientific Research with the material assistance of the Rockefeller Foundation. Academic representatives of Belgium, France, Great Britain, Holland and the United States were present, and a detailed account of papers presented and discussions relevant thereto is to be found in three consecutive issues of the Revue de l'Institut Francais du Pétrole et Annales des Combustibles Liquides $(4$, No. 7, 275 ; No. 8, 363 ; and No. 9, $439 ; 1949$ ).

Within the terms of reference of this conference, a wide choice of subjects was presented by thirty-five delegates to between sixty and eighty members. It included, as recorded in No. 7 of the Revue, flamespeeds at atmospheric pressure and the influence of catalysts; researches on the source of issue of hydrocarbon 'bandes de flammes'; slow oxidation of hydrocarbons; the role of formaldehyde in the oxidation of hydrocarbons such as methane and ethylene; the slow oxidation of di-isopropylether over the temperature-range $360^{\circ}-460^{\circ}$ C. ; oxidation and pyrolysis - the effect of small quantities of oxygen on the pyrolysis of organic vapours with special reference to acetaldehyde; the influence of the nature and size of the walls on the birth and the breaking of reaction chains, and the action of small quantities of several vapours, gases and solid substances ; propagation of flame in ethylene - air mixtures; flame-movement mechanism in gaseous mixtures and the phenomenon of projection of active centres; what happens on ignition of a bubble of hot gas.

No. 8 of the Revue covers papers on the mechanism of initiation of chains in the thermal reaction between hydrogen and oxygen; the theory of burning, extinction and stabilization of flames; processes of combustion in two stages of the higher hydrocarbons and their derivatives; the emission and absorption spectra of the hydroxyl radical in various flames at low pressure; mechanism of combustion of a pure cyanogen flame and its decrease in radiation when hydrogen, chlorine or nitrous oxide is present; an account of research into the mechanism of combustion of methane; vapour tension and heat of sublimation of carbon.

Included in No. 9 are studies in the kinetics and inhibition of burning methane; the active combustion of methane; the temperatures of spontaneous burning of air-diethyl acetate mixtures; the influence of the state and of the evolution of walls on burning temperatures with air - hexane mixtures; kinetic study of diethyl - acetal - air flames and air - $n$ hexane; the technique of using a mass spectrometer to detect reaction intermediates in the decomposition and combustion of simple hydrocarbons. A method is described for measuring efficiencies of fast reactions of atomic hydrogen with olefins. It is also shown that reactivity of any particular bond in a hydrocarbon may be affected by neighbouring groups in the molecule. Concluding papers discuss influence of walls and gas diluents on the sphere of inflammability of hydrogen; the use of free valence number in studies of chemical reactivity; the influence of a special change of size of the open end of a cylindrical tube on flame propagation in gaseous mixtures; certain hypotheses adopted in calculating speeds of deflagration from measurements in a spherical bomb, and finally the influence of turbulence on the mechanism of combustion reactions in the gaseous phase. Altogether, this is a most comprehensive exposition of an extremely complex subject.

H. B. Milnerer

\section{NATIONAL RESEARCH COUNCIL OF CANADA REVIEW FOR 1948}

$T$ HE review of the National Research Council of Canada for the year ended December 31, 1948*, describes the work of the Council in rather greater detail than is done in the annual report and, besides a directory of staff and list of research grants, includes a more up-to-date account of the activities of the year. The staff employed by the Council numbered more than 2,700, and, of the thousand skilled workers employed on the Atomic Energy Project at Chalk River, half were men of science. Progress at Chalk River in operations and in scientific output continued; the experimenta] NRX reactor (heavy-water pile) gave the highest neutron flux density of any research pile then in existence, and, in addition, opportunities for fundamental investigations permitted irradiation of nearly six hundred samples for the production of radioactive isotopes. The Isotopes Branch distributed forty different isotopes to twenty. two institutions. The Chemical Engineering Research Branch was enlarged, and a new laboratory was being constructed for the separation of isotopes. As a result of co-operation, many centres in Canada started working on the use of radioactive isotopes as tracers in agricultural, biological, medical, chemical, physical and metallurgical research.

A more reasonable balance was established between applied and fundamental research in the Division of Applied Biology. Work continued on refrigerated storage of meat, processing of liquid and dried eggs, and dairy products, in which it was found that the baking properties of sugar-egg powders improve as the size of the atomizer nozzle is reduced, within. practical limits. Considerable progress was made in the adaptation to Canadian requirements of the Fritz continuous butter machine. Interesting results were obtained with dried whey as a component in sponge

* National Research Council of Canada, Review, 1949. (N.R.C. No. 1997.) Pp. 252. (Ottawa : National Research Council of Canada, 1949.) 75 cents. 